\title{
The influence of the communicative strategy on the degree of protectability of texts in the Modern Political Discourse
}

\author{
Elena Grass ${ }^{1, *}$, Tatyana Schevchenko $^{1}$, Inna Ivanova $^{1}$ and Maria Mishatkina ${ }^{1}$ \\ ${ }^{1}$ Volgograd State Socio-Pedagogical University, 27 Lenina Ave., 400066, Volgograd, Russia
}

\begin{abstract}
The article is devoted to the understanding of information in political discourse. The main types of the text security and their inter-relationship with the degree of the addressee intention are considered. The article reveals the analysis of the intentional component and the degree of its influence on the communication strategy between the addresser and the addressee on the basis of texts drawn from press-conferences and interviews. The key communication strategies that influence the nature of text security are identified.
\end{abstract}

\section{Introduction}

Speech is the main source and type of information transmission. Along with being informative, it also includes the most important characteristic, that of impact. At this, communication can occur not only to influence the participants of communication, but also to transmit and store a certain type of information. Political discourse includes these speech characteristics and opens up new possibilities for information understanding.

The purpose of this article is to determine the interrelationship of the addressee's intention with the degree and types of text security.

\section{Materials and methods}

The methods of information protection in the political discourse are described and analyzed.

Political discourse, as a representative of the persuasive (i.e. has the power of persuasion), is characterized by the power of manipulation and influence, the purpose of which is to influence the mental model of the addressee.

E.I. Sheigal points out that politics is a special sphere of human activity in which various speech actions are intertwined [1]. In the center of political discourse, like many others, the genres that best reflect the main purpose of this type of discourse, that is, the struggle for leadership in social life is intertwined.

However, O.V. Popova underlines that politicians often try to "disguise their goals" [2], in other words, conceal or disguise their real intentions and goals. At this, they use certain strategies and techniques such as metaphors, nominalization, paremiological units, intonation, etc., which affect the understanding of the message to protect specific information.
The recipient's understanding or misunderstanding of the information depends on their mental model. T.A.Van Dyck notes that the recipient must have a certain amount of knowledge to understand the implicit intentional basis of the message. Linguistic researchers understand intention as a communicative or verbal intention, i.e. the intention and purpose of a future statement. N.I. Formanovskaya underlines that "speech intention is a meaning of reactive utterance mental substrate, which is reflected in its semantics as one of the substantial components of the human inner world» [3]. D.V.Shapochkin remarks that the intentional basis or communicative intention appears in the political discourse and forms specific strategies prior to the implementation of the statement [4].

\section{Results}

In choosing a communication strategy for hiding and protecting the information, the addresser follows the basic strategy of this communication zone. T.A. Van Dyke distinguishes several cognitive-speech strategies in political discourse: evasion of response, the use of standard expressions for generalization, giving an example, intensifying, contrasting statements, mitigation, presupposition, implication, assumption, indirect speech act [5].

The addresser can choose any strategy to hide the information, but his choice will depend on the audience or the identity of the addressee. The addressee, in turn, being a participant of the communicative act, perceives the information and interprets it.

Van Dyck draws attention to the strategy flexibility and its ability to change in the process of communication.

I.N. Borisova distinguishes such concepts as a strategy and an intention: the intention is the idea of the speaker, the strategy is one of the options for the

\footnotetext{
* Corresponding author: grasslena@gmail.com
} 
organization of communicative communication. She points out two types of the strategy [6]:

1) conscious strategies, i.e. strategies that are thought out in advance and are the addresser's intention;

2) subconscious strategies that are not based on a specific plan or intention, but are formed in the process of communication and are spontaneous.

Many linguists understand tactics as the speech steps that are made to achieve the goal and implement the strategy.

Thus, a communicative strategy is a speech action that includes a certain theoretical plan (intention) and is implemented with the help of communicative tactics.

Not all strategies are suitable for prevarication and hiding information, but we will consider and analyze the most representative ones.

In analyzing the concept of the text security, it should be noted that any communication act which takes place between an addresser and an addressee, does not always occur for the purpose of understanding each other. The intentional nature of the addresser's statement may be based on the concealment or protection of certain data. In political discourse, communication is often based on implicit intentions. Implicit intention depends on a politician's goals and motives, and it is not always possible to understand the information that is based on this kind of intention. However, most often a speech is based on the explicit intention of the addresser, but despite this, the awareness and understanding of the information is difficult.

In political discourse, the text security is understood as conscious (intentional) or unconscious (unintentional) information concealment. Depending on the implicit and explicit addresser's intention, his further statement affects the degree of the text security. On reviewing and analyzing a number of V. Putin's statements at press conferences and his interviews, we have identified some communication strategies that have an impact on the text security degree in political discourse.

\section{Discussion}

The most prominent representative of such strategies is communicative absenteeism or evasion of response in order to hide certain information. This strategy is used to deliberately hide the information in political discourse and is implemented by a number of tactics. Here are some examples to be concerned:

At the press conference with the President in 2016, the question was whether he would take part in the elections in 2018. That is what he said:

"No, it does not mean that I have made such a decision for myself. But this means that we must adjust our medium-term, long-term plans, without which no country can live. Nor will Russia" [7].

The politician uses the opposition of "no, it does not mean..., but it means..." thereby leading the audience into difficulty. The addressees do not understand whether he will participate in the elections or not. The intention is clearly implicit, and the addresser uses a strategy of evasion or prevarication.

During the direct link with the President in 2018, Putin was asked when he had come to believe in God. The answer was:

"This is a very personal question. You know, it is very difficult to talk about it in public, but in my opinion, every person is already born with the belief in God without realizing it, only different people at different times and under different circumstances begin to realize it.

In any case, say, during the Great Patriotic War, when even the most inveterate and notorious atheists stood up in the trenches and went on the attack, I am sure that each of them were thinking about God.

Therefore, there are people who understand this without any extreme situations, but nearly every person is certain to think about it when they get into some extreme situation" [8].

In his statement, he evades the direct answer, hiding the information whether he believes in God or not, using the words "...in my opinion, every person...", the politician uses the tactics "from the Particular - to the General." Drawing the audience's attention away from his personality, he talks about faith from the philosophical point of view.

Speaking about the addresser's intention, it should be noted that initially it seems that it is explicit. But to answer a question on the given topic does not mean to speak out some specific information. The addressees listen and perceive the information, but the interpretation of the data they get may be different.

During the direct link with the President in 2018, he answered the question about altering the retirement age:

"As for the retirement age, you know my position, I have always treated it with the utmost care and cautious.

So, what would I like to draw your attention to? One of the key tasks that I have formulated for the Government is to increase the pensioners' incomes, and at a significant level at this.

The government will have to provide this in the very near future, of course, because this is the solution of another important task - to halve the number of people living below the poverty line.

So, what measures will be proposed by the Government to solve this key problem, we are to get to know in the near future. I hope that the Government will do it, and then we will discuss and talk about the measures proposed by it.

But I want to stress once again that the key task in the entire pension system is to significantly increase pensioners' welfare and income" [9].

This example is of utmost interest, because the people of Russia already know the answer to this question: we are in for the increase in the retirement age from January 1, 2019. But when the President was asked this question in June 2018, he clearly used the strategy of "dodging" and did not answer directly. Using the words “... highly...", “... one of the key tasks...", he obviously shows that he is concerned with this topic as well as ordinary citizens. However, he shifted the responsibility for the decision to the Government, using 
the tactics of "responsibility shifting". By taking this tactic, the President thus protects the information that he already knows, but claims that everything depends on the Government.

The next strategy that policymakers use is the synthesis strategy. Such strategy is most often used to mitigate real information by providing various examples that show that the situation is not isolated or unique. In this case, by using this strategy, the addresser partially hides the information. Now we consider the following examples:

In his interview with the American TV channel Fox News, President Putin very often summarizes the information, for example, when he was asked whether it was easy to deal with President Trump, he said:

"Firstly, as for the point why we talked like intelligent people to each other. Are you surprised? There's no use meeting, going to Helsinki that means flying overseas for him and flying from Moscow for me, to curse each other and blame each other. This is not in line with the world diplomatic practice.

Then, what's the use meeting if we intend to scold each other and worsen the relationship? We have gathered and met to find ways to improve our relations, but not destroy them completely. This is the first part of my answer.

The second part is whether we have any compromising material. We do not and it cannot exist. I do not want to offend President Trump and I risk being impolite, but before he announced that he would be a presidential candidate, he had not been of any interest to us.

He is a rich man, but there are a lot of rich people in the United States. He used to be in the construction business, he used to hold beauty contests. It could never have occurred to anyone that he would someday be President of the United States. He never talked about his political ambitions. So that is just nonsense. You understand, as I said at the press conference, 550 major American businessmen have come to St. Petersburg, each of them is probably more significant than Mr. Trump. And do you think we are totally with all the work, our security service is running about eavesdropping and spying?

First of all, unlike you, we don't do that. You must be judging for yourselves. Secondly, we do not have so much money, neither strength, no possibilities to totally follow everybody. This is out of our plans, it is impossible, and of course, we did not do anything like that towards Trump" [9].

Having studied his answer, we can say that it is very structured: an addresser uses "this is the first part of my answer...", "the second part is...", "First of all.., secondly..." paying attention of the addressee on the consistency and argumentation of the information which he is appealing. Here, the addresser uses the tactics of "persuasion". Then he appeals to the tactics "from particular example to the general": "...He is a rich man, but there are many rich people in the United States...", " ...550 major American businessmen arrived in St. Petersburg, each of them is probably prominent than Mr. Trump...". The next "provoking" tactic: "And You think, we are totally working with all and our secret service is running after all, overhearing and peeping?", “Are you surprised?" Using different tactics, Putin V.V. implements a strategy of generalization, which is based on a hidden intention. The addressee perceives the information, interprets it and analyzes the received data. The information, in this case, will be partially protected, as the addresser, from one side, doesn't express negative emotions, but on the other hand, uses the strategy of generalization, and strange personnel attitude of Putin V.V. to the President Trump.

In the same interview to Putin V. V., a question was asked of his political opponents who were attacked, on what, he answered:

«V.Putin: First of all, we all have a lot of political opponents. Take any person who is engaged in public...

Christopher W. Wallace: But they are alive.

V.Putin: Not always. Didn't they kill your presidents? You forgot it? Where Kennedy was killed, in the USA or in Russia? And what happened to King? What happens during the clashes between the police and the members of civil society, for example the ethnic black organizations? Does it happen in our country or in yours? It happens in your country. You have a lot of your problems.

And the fact that in Russia there are criminal manifestations, yes, unfortunately, it is so. Russia is still in her state formation. Unfortunately, there are many manifestations of this kind. We fight against it and bring to justice those people who are responsible for it» [9].

Analyzing this example, it is obvious, that the addressee also uses a generalization strategy (...we all have a lot of political opponents, and the president Trump has also a lot of political opponents, ... there are many manifestations of this kind) focusing on the fact that this case is not isolated and many politicians face it. The addressee perceives the information, interprets it and comes to the conclusion that on the one hand he admits the existence of a problem (...in Russia there are criminal manifestations, yes, unfortunately, it is so), but on the other hand using the tactic "from particular example to the general" (Take any person who is engaged in public...) he doesn't give an exact answer, thus, partially conceals the information.

In analyzing the following kind of the text security, it should be noticed that this type is based on "unconscious" data hiding. Here, it must be emphasized that on the one hand an explicit intention for the addresser is meant (he does not hide anything and in his message he wants to convey the idea to the addressee), but on the other hand, the recipient does not understand or understands the message incorrectly. In this communicative situation, the addressee's goal is to convey information to the listener, but for some reason, he does not achieve this goal. Information remains protected (misunderstood by the addressee). For example, at a press conference with Putin V.V. in 2017, he was asked about the absence of an influential opposition candidate, to which he said:

"V.Putin: To sharpen your question, I saw a girl with a raised poster on which is written: "Putin, byebye". 
Replica: "Putin is babay".

В.Путин: "Ah, babay. "Getting older monkey got a weak eyes". I'm sorry.

D.Peskov: Please, give the microphone.

Question: Good afternoon!

It's a language gap. Today everyone is afraid of me. That's written here: "Putin is babay" - it's in Tatar "granpa is Putin", the children call you in such a way in our republic. And my questionis associated with children and with the language. If it is possible, I'll ask now or after the colleague" [10].

In this communicative situation, the aim of the girl who wrote the poster, was to attract the President's attention and to show that the question would be connected with the Tatar language, but the President (the addressee) interprets it all by mistake. Besides, he used it for a question with which this information has nothing to do. Here the intention of the addressee is clearly explicit, but due to the language gap, the information refers to an unconscious type of text security.

\section{Conclusion}

Let's summarize the main results of the research. The aim of communication in political discourse is not only to influence the audience, but also to conceal certain information. The participants in a conversation can protect information explicitly (consciously) or covertly (unconsciously). Understanding in political discourse depends on a number of factors. Firstly, it is necessary to take into account the intentions of the addressee: it depends on his communicative intentions, they can be explicit and implicit. Implicit intentions are the basis for future statements, the intention of which is the concealment of certain information. Secondly, the addressee uses a number of strategies that realize the idea of "text security", that is the protection of certain information. Having analyzed a number of statements of the famous politician, it was found that the degree of implicit intention affected the strategy of communication between the addresser and the addressee. Therefore, the more the addressee intends to hide the information, the more it affects the choice of the strategy.

Having studied a number of strategies that the addressee uses in his speech, it was found that the strategy of communicative absenteeism or evasion of response, mostly used in communication in political discourse. Using this strategy, the addressee intentionally is eager to hide the information. In order to realize this strategy, the addressee uses a number of tactics: a tactic "from particular to the general", a tactic "shifting responsibilities" (the addressee has already known the particular information, but he talks to everybody that nothing depends on him and the decision would be taken by somebody else); "a tactic of tangle" (the addressee gives uncertain answers to some questions which lead the addressee to the difficulty and the interpretation of the obtained information is difficult).
The addressee uses the generalization strategy in order to hide the information in political discourse. In this case, the politician's speech has a double intention: on the one hand, the addressee acknowledges the existence of a problem or a question, but on the other hand he emphasizes that this situation is not unique and gives a number of examples which distract the addressee's attention and takes him away from the real information that he's interested in.

Unconscious protection of information is based on the explicit intention of the addressee, but the understanding of these data by the addressee depends on various factors. The main factor which influences the misunderstanding is the unconformity of the mental model of the sender and the addressee. Understanding and acceptance of certain information for one person is not clear for the other conceptually. The security of texts in political discourse is one of the most important characteristics influencing the understanding of information.

\section{References}

1. E I Sheigal Volgograd: Peremena Semiotics of political discourse: monograph 368 (2000)

2. V Popova Saint-Petersburg: Saint-Petersburg State University Political identification in the conditions of society transformation: monograph 258 (2002)

3. N I Formanovckya Russian language abroad 13, 42-47 (1996)

4. D V Shapochkin Tyumen: Tyumen State University Political discourse: cognitive aspect: monograph 260 (2012)

5. T A Dake Blagoveshchensk: BGK Language. Knowledge. Communication 308 (2000)

6. I N Borisova Saratov: State Study and Science Centre College Genres of speech: Collection of scientific articles 81-96 (1999)

7. Live Talk with Vladimir Putin Retrieved from: https://www.youtube.com/watch?v=kv3tcDiH MWI (2016)

8. Live Talk with Vladimir Putin Retrieved from: https://www.youtube.com/watch?v=ZFrhnDlL WH4 (2018)

9. Vladimir Putin's interview to TV-channel "Fox News" Retrieved from: https://www.youtube.com/watch?v=AA03Q87 $\underline{\mathrm{KlZ8}}$ (2018)

10.Big Press Conference of Vladimir Putin Retrieved from: https://www.youtube.com/watch?v=AXO5zY8 $\underline{\mathrm{Iu} 2}$ (2016)

11.E M Safronofa, L S Beylinson, N V Zolotykh, $\mathrm{T} \mathrm{U}$ Shevchenko International Journal of 
Enviromental \& Science Education 11 (16), 8968-8980 (2016)
12.T U Shevchenko, G G Slyshkin, A A Moseyko, K G Korovina SHS Web of Conferences 50, 01173 (2018) 